\title{
Membrane-Based Seawater Desalination: Present and Future Prospects
}

\author{
Gary Amy,1,2,3 (gamy@clemson.edu), \\ Noreddine Ghaffour ${ }^{3}$ (noreddine.ghaffour@kaust.edu.sa), \\ Zhenyu Li ${ }^{3}$ (zhenyu.li@kaust.edu.sa) \\ Lijo Francis ${ }^{3}$ (lijo.francis@kaust.edu.sa), \\ Rodrigo Valladares Linares ${ }^{3}$ (rodrigo.valladares@kaust.edu.sa), \\ Thomas Missimer ${ }^{4}$ (tmissimer@fgcu.edu), and \\ Sabine Lattemann ${ }^{3}$ (sabine.lattemann@uni-oldenburg.de) \\ *Corresponding Author \\ ${ }^{1}$ College of Engineering and Science \\ Clemson University, Clemson SC 29634 USA \\ ${ }^{2}$ Chemical and Biomolecular Engineering \\ National University of Singapore, 119077 Singapore \\ ${ }^{3}$ Water Desalination and Reuse Center, \\ King Abdullah University of Science and Technology, \\ Thuwal 23955 Saudi Arabia \\ ${ }^{4}$ Florida Gulf Coast University, \\ Fort Myers FL 33965 USA
}

\begin{abstract}
Given increasing regional water scarcity and that almost half of the world's population lives within $100 \mathrm{~km}$ of an ocean, seawater represents a virtually infinite water resource. However, its exploitation is presently limited by the significant specific energy consumption $\left(\mathrm{kWh} / \mathrm{m}^{3}\right)$ required by conventional desalination technologies, further exasperated by high unit costs $\left(\$ / \mathrm{m}^{3}\right)$ and environmental impacts including GHG emissions $\left(\mathrm{g} \mathrm{CO}_{2}-\mathrm{eq} / \mathrm{m}^{3}\right)$, organism impingement/entrainment through intakes, and brine disposal through outfalls. This paper explores the state-of-the-art in present seawater desalination practice, emphasizing membrane-based technologies, while identifying future opportunities in step improvements to conventional technologies and development of emerging, potentially disruptive, technologies through advances in material science, process engineering, and system integration. In this paper, seawater reverse osmosis (RO) serves as the baseline conventional technology. The discussion extends beyond desalting processes into membrane-based salinity gradient energy production processes, which can provide an energy offset to desalination process energy requirements. The future membrane landscape in membrane-based desalination and salinity gradient energy is projected to include ultrahigh permeability $\mathrm{RO}$ membranes, renewable-energy driven desalination, and emerging processes including closed-circuit RO, membrane distillation, forward osmosis, pressure retarded osmosis, and reverse electrodialysis according various niche applications and/or hybrids, operating separately or in conjunction with $\mathrm{RO}$.
\end{abstract}

Keywords: membranes, seawater desalination, specific energy consumption, greening of SWRO

\subsection{Introduction}

Given an increase in regional freshwater scarcity, interest in, and the practice of, seawater desalination are rapidly increasing. While mature thermal desalination technologies exist (e.g., multi-stage flash (MSF) and multi-effect distillation (MED)), 
interest has turned to membrane-based technologies because of more favorable energetics (i.e., lower specific energy consumption $\left(\mathrm{kWh} / \mathrm{m}^{3}\right)$ ), with seawater reverse osmosis (SWRO) presently considered as the conventional technology. However, SWRO is still an energy-intensive technology with associated greenhouse gas (GHG) emissions and other environmental impacts (e.g., organism impingement/entrainment at intakes and brine disposal at outfalls). Thus, there is an interest in both the greening of SWRO and emerging technologies beyond SWRO.

\subsection{Present Status of SWRO}

Presently, seawater reverse osmosis (SWRO) dominates the global desalination market (GWIMDR, 2015) based on installed capacity, having surpassed thermal technologies (MSF and MED) that are common in the Gulf Cooperation Council (GCC) and Middle East-North Africa (MENA) regions; of the 2015 installed desalination capacity of 86.5 $\mathrm{Mm}^{3} /$ day, the shares of $\mathrm{RO}$ (versus other processes) and seawater applications (versus other sources) are $65 \%$ and $59 \%$, respectively. While SWRO annual installed capacity is now globally dominating over thermal technologies, its emergence into GCC-MENA region, particular in the Gulf of Arabia, has been slow because of higher-salinity feed waters that are impacted by hydrocarbons and Red Tide events.

With the integration of energy recovery devices (ERD) in SWRO during the early 1990s, considered a disruptive technology at the time, specific energy consumption has been significantly reduced from 5 to $10 \mathrm{kWh} / \mathrm{m}^{3}$ to its present $3-4 \mathrm{kWh} / \mathrm{m}^{3}$ with the most efficient ERD systems (Ghaffour et al., 2013); most of this energy (about 85\%) is associated with the SWRO process itself with lesser energy requirements (about 15\%) are for other SWRO system components (i.e., intake, pre-treatment, and posttreatment). While there are opportunities for reducing the energy consumption of pretreatment, our discussion will of energetics will focus on the most energy-intensive system component, the $\mathrm{RO}$ process itself.

Dual media filtration (DMF) remains the conventional pretreatment process, however, integrated membrane systems (IMS) with ultrafiltration (UF) pretreatment, UF-SWRO, are becoming more common (Voutchkov, 2010), especially for difficult-to-treat waters. Both UF and dissolved air flotation (DAF) are receiving increasing attention for their potential resilience during Red Tide events (harmful algal blooms (HABs)) (e.g., experienced at the Gulf of Arabia) (Villacorte et al., 2015). Subsurface intakes have recently been shown to provide a significant degree of pre-treatment in acting as a biological filter to remove biodegradable organic carbon and reduce associated $\mathrm{RO}$ membrane biofouling (Missimer, et al., 2013). Effective pretreatment can affect the energetics oft the RO step by reducing fouling.

Given a virtually infinite supply of seawater, SWRO facilities are typically run as onepass systems with recoveries of $35-60 \%$; some facilities incorporate a second (split stream) pass for boron removal (Rahmawati et al., 2012). Acid addition and/or antiscalant addition continue to be practiced for scaling control and chlorine-sodium bisulfite for biofouling control although interest in alternative pre-disinfectants is increasing: chloramines (carried through the $\mathrm{RO}$ membrane as a residual) or chlorine dioxide (followed by sodium bisulfate before the membrane) as practiced at the Tampa Bay SWRO facility. SWRO trends include larger capacity facilities (e.g., the Sorek facility in Israel, 624 MLD (2013)), larger elements (16-inch), vertical orientation for RO 
membrane modules and pressure vessels (to permit air scouring), and improved operations (fouling control and sensors). While present SWRO practice serves the desalination industry well, it remains an energy-intensive technology with significant environmental impacts.

\subsection{The Greening of SWRO}

The major environmental impacts of SWRO facilities include: greenhouse gas (GHG) emissions associated with (fossil fuel) energy use, entrainment/impingement of organisms by (open) intakes, brine disposal impacts on coastal marine ecosystem, marine pollution, chemical use, land use, and material use. However, sustainable solutions are available to mitigate these impacts (Lattemann et al., 2010; Lattemann, 2010).

GHGs can be offset by minimizing (fossil fuel) energy use, using renewable energy, or practicing energy compensation (i.e., taking energy from the grid and compensating with renewable energy) (Ghaffour et al., 2015); moreover, energy consumption is directly correlated with GHG emissions. Moreover, the source of fossil fuel energy (e.g., natural gas or coal) can affect the magnitude of GHG emissions (Lattemann, 2010). Entrainment/impingement of organisms can be mitigated by subsurface intakes or submerged intakes with low-velocity intakes. Concentrate discharge can be managed by dispersion through a multiport diffuser system in a suitable marine site, controlling the extent and concentration of the salinity plume. Treatment of all backwashing and cleaning wastes can reduce marine pollution. Chemical use can be minimized by low chemical technologies (e.g., pretreatment by subsurface intakes or ultrafiltration without coagulant addition), which can eliminate the need for chemical pretreatment or cleaning entirely. Furthermore, harmful chemicals can be substituted by less toxic, more degradable substances. Land use and landscape impacts can be minimized through site selection. Material use can be offset by improved recyclability and reuse of materials, including replaced SWRO modules.

\subsection{Step Improvements in SWRO Performance}

Several RO membrane manufacturers have released new SWRO membrane products that include: (i) low fouling membranes, (ii) enhanced boron-rejection membranes, and (iii) inorganic-organic nanocomposite membranes with purported higher permeability. The main step improvement for SWRO would be reduced specific energy consumption $\left(\mathrm{kWh} / \mathrm{m}^{3}\right)$ and associated $\mathrm{GHG}$ emissions ( $\left.\mathrm{g} \mathrm{CO}_{2}-\mathrm{eq} / \mathrm{m}^{3}\right)$ through higher permeability/lower pressure RO membranes. Fouling-resistant membrane can also significantly reduce energy consumption, given the increase in transmembrane pressure (TMP) needed to maintain constant $\mathrm{RO}$ flux during an operational/cleaning cycle. Further advances in material science offer the promise of ultrahigh permeability (UHP) $\mathrm{RO}$ membranes through a new generation of nanocomposite, biomimetic (aquaporins and synthetic water channels), and possibly graphene membranes (Pendergast and Hoek, 2011). However, there is a limit to lowering energy by increasing permeability because one cannot escape the inherent osmotic pressure penalty (about 28 bar for seawater, increasing to double along the element/pressure vessel assuming a $50 \%$ recovery); operating pressure to overcome $\mathrm{RO}$ membrane resistance and provide flux is typically about $10-20 \%$ above the highest osmotic pressure condition in the element/pressure vessel. Any improvements in specific energy consumption through 
higher permeability membranes should not compromise product water quality in terms of salinity and specific problematic salt constituents such as boron. Thus far, only inorganic-organic nanocomposite RO membranes have been commercialized for seawater desalting while other UHP RO membranes are still under development (Subramani and Jacangelo, 2015).

Biomimetic membranes, based on aquaporins (a water-channeling protein), are being developed as UHP RO membranes; with impregnation of aquaporins (or vesicles) into polymeric matrix, aquaporins can provide water channeling/gating, leading controlled water permeability and ion selectivity. One company has commercialized an aquaporin tap-water RO membrane but it is not applicable to SWRO. There are also protein ion channels that transport ions rather than water. A constraint to aquaporin membranes is the cost of the industrial production of aquaporins, e.g., Aquaporin Z from E. Coli cultures. Given concerns about aquaporin stability under long-term operation, there is recent interest in the use of synthetic water and ion channels (Shen, et al., 2015) as an attempt to mimic aquaporins while being more stable and easier to manufacture.

Other energy trends are renewable energy-driven SWRO (Ghaffour et al., 2014), especially using solar energy (the largest solar-SWRO plant $\left(30,000 \mathrm{~m}^{3} /\right.$ day) in the world is under construction in Saudi Arabia), and energy compensation by wind energy in Australia. While use of renewable energy does not necessarily reduce specific energy consumption, it provides a reduction in GHG emissions. This interest in renewable energy is now evolving toward integrated systems beyond just electricity provided solar PV panels or wind turbines.

The Energy Task Force of the International Desalination Association has targeted a $20 \%$ reduction in energy requirements for SWRO in the near term, which suggests a target of below $3.0 \mathrm{kWh} / \mathrm{m}^{3}$. Given that the thermodynamically minimum energy requirement for seawater desalination is about $1.2 \mathrm{kWh} / \mathrm{m}^{3}$ for a typical $50 \%$ recovery system $\left(0.78 \mathrm{kWh} / \mathrm{m}^{3}\right.$ for $0 \%$ recovery) (Elimelech and Philip, 2011), we can assume a practical thermodynamic limit of $1.0 \mathrm{kWh} / \mathrm{m}^{3}$. Based on present SWRO (process only) conditions $\left(>2.5 \mathrm{kWh} / \mathrm{m}^{3}\right)$, we propose a medium-term ( $3-5$ years) target for emerging seawater desalination processes of $2.0 \mathrm{kWh} / \mathrm{m}^{3}$ and a longer-horizon (> 5 Years) target of $1.5 \mathrm{kWh} / \mathrm{m}^{3}$. The difference between these two values can be attributable to further material science advances, hybridization, and process intensification over time.

\subsection{Emerging Technologies Beyond SWRO}

A semi-batch (closed circuit) mode of RO operation, designated as closed circuit RO (CC-RO), provides an opportunity for further reduction in SWRO energy consumption (Efrati, 2011). In CC-RO, standard RO components are incorporated in the CC-RO system design. CC-RO is operated as a semi-batch process (versus steady-state conventional $\mathrm{RO}$ ) and runs at near 100 percent recovery (up to $98 \%$ recovery in a single stage). It does not produce concentrate for a period, then goes through a flush cycle, and then resumes closed circuit operation. Cross-flow is provided by a circulation pump to limit fouling/scaling. CC-RO is being projected to attain a $15-20$ percent reduction in specific energy consumption (Efrati, 2011), suggesting that it would approach 2.5 $\mathrm{kWh} / \mathrm{m}^{3}$ in seawater desalination although the operational complexity and the additional costs of the system are considerations. 
There are several emerging low-energy desalination technologies that can potentially approach a targeted threshold of $2.0 \mathrm{kWh} / \mathrm{m}^{3}$ while desalting seawater. These include membrane-based processes: forward osmosis (FO) and membrane distillation (MD); low-temperature thermal processes: adsorption desalination $(A D)$ and low temperature distillation (LTD); and electrochemical desalting processes such as capacitive deioninzation (CDI) (so far, mostly used for low salinity feeds, e.g. brackish water desalination). We will focus on the energetics of the membrane-based processes; FO, $\mathrm{MD}$, and various hybrids; and the integration of membranes into CDI. However, there are caveats that must be recognized in meeting the targeted energy threshold, as will be discussed.

The discussion of emerging membrane-based processes can be extended from desalination processes; RO, FO, and MD; into salinity energy gradient processes such as pressure retarded osmosis (PRO) and reverse electrodialysis (RED). These salinity gradient processes can be integrated into existing SWRO plants, e.g., SWRO-PRO, to partially offset energy consumption by SWRO.

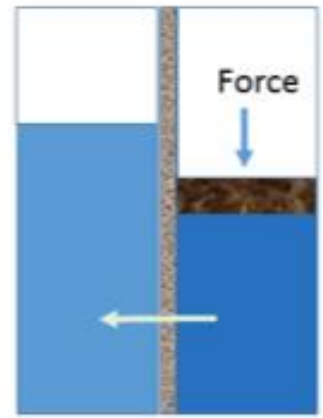

RO

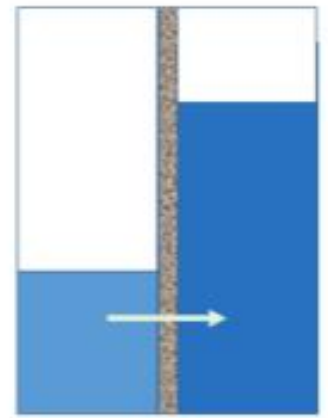

FO

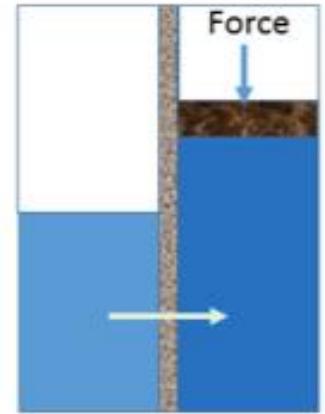

PRO

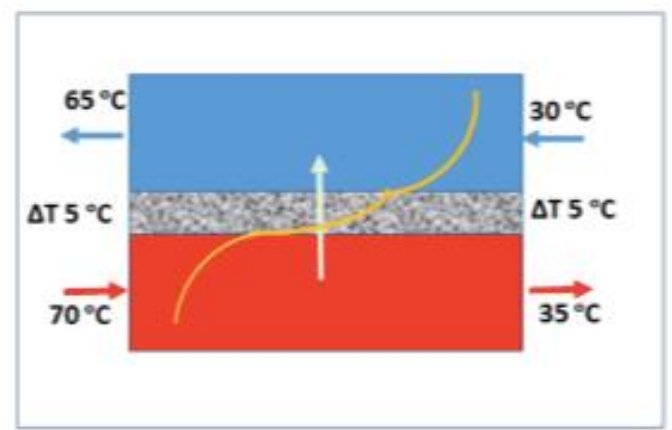

MD

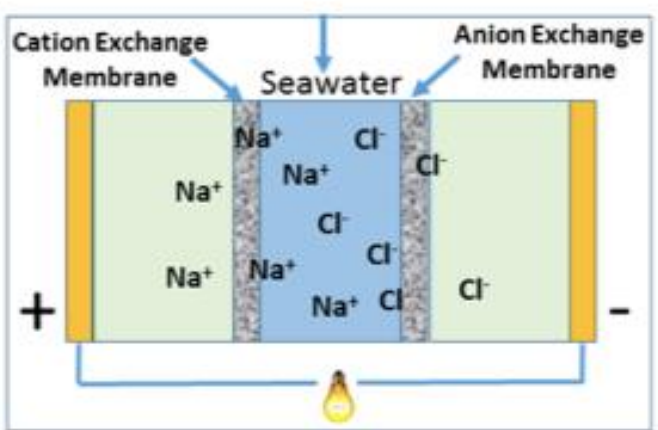

RED

Forward osmosis (FO) is a process involving the extraction of water from a lowerosmotic pressure feed solution into a higher-osmotic pressure draw solution across an FO membrane, driven by an osmotic-pressure gradient. For FO, there has been significant progress in the evolution of higher-flux, lower-salt leakage, commerciallyavailable FO membranes, with one company recently commercializing an aquaporin FO membrane. There has also been recent progress in developing hollow-fiber FO membranes (Chung et al., 2015); a new prototype hollow fiber FO membrane has shown a flux of $>40 \mathrm{LMH}$ against a draw solution of $2 \mathrm{M} \mathrm{NaCl}$ (Sukitpaneenit and Chung, 2015). Progress is also evident in devising more effective draw solutions, driven by the goals of higher osmotic pressure, lower reverse draw solute flux, easy 
regeneration, non-toxic, and lower cost. The carbon dioxide-ammonia thermolytic draw solution has evolved into commercial applications (McGinnis et al., 2013), with temperature-sensitive hydrogels showing promise as draw solution. Moreover, lowgrade waste heat (e.g., $60^{\circ} \mathrm{C}$ ) is adequate to recirculate these thermolytic components (Elimelech, and Philip, 2011). Several commercial FO companies are (i) operating in niche applications (e.g., brine concentration), (ii) fabricating FO membranes (presently limited to flat sheet/spiral wound/plate-and frame membranes/modules), and (iii) marketing thermolytic draw solutions (utilizing waste heat for component recirculation).

The FO process itself can directly desalt seawater as a feed solution by employing a higher-osmotic pressure draw solution, however, the energetics of product water recovery and draw solution component recirculation are not favorable (MsGovern and Lienhard, 2014). Alternatively, the FO process can potentially become a lower-energy desalination technology, if coupled with low-pressure RO (LPRO) as a hybrid (Valladares Linares et al., 2014; Hancock et al., 2012), in which indirect desalination is achieved. The FO step dilutes seawater (acting as a draw solution) with a low-value impaired-quality water (e.g., wastewater effluent) acting as a feed solution, and the diluted draw solution then further processed by low-pressure RO (LPRO). The FO-RO sequence provide a double barrier for organic micropollutants and pathogens in the wastewater in what is, in essence, a direct potable reuse (DPR) system. Given the wastewater reclamation value of secondary effluent and the energy investment to provide secondary wastewater treatment, there has been recent work on using primary effluent in the FO-LPRO hybrid (Valladares et al., 2013). The resultant concentrated feed solution can then potentially be treated by anaerobic digestion with biogas $\left(\mathrm{CH}_{4}\right)$ production; here, the main challenge is FO membrane fouling control. The produced biogas $\left(\mathrm{CH}_{4}\right)$ about $1.5 \mathrm{kwH} / \mathrm{m}^{3}$ for FO concentration factor of 1 (Valladares et al., 2013), can further offset the energy consumption of the overall FO-LPRO system. A life cycle assessment by Valladares Linares et al. (2016) showed that compared to SWRO as a baseline, the FO-LPRO system has a higher capital cost but a significantly lower operations cost due to savings in energy consumption and fouling control, with a lower unit cost $\left(\$ / \mathrm{m}^{3}\right)$. Further operational optimization of the FO-LPRO hybrid, e.g., FO concentration factor, is still needed. Shaffer et al. (2015) stated that the "FO process is not intended to replace RO, but rather is to be used to process feed waters that cannot be treated by RO"; the FO-LPRO hybrid does not violate this statement in that FO step provides pretreatment (salinity and fouling reduction) for the subsequent LPRO step.

Membrane distillation (MD) is a membrane process, driven by a thermal (temperature) gradient, with water vapor transported across a hydrophobic microporous membrane using a significantly lower temperature than conventional distillation at very low operating pressures (nearly $1 \mathrm{bar}$ ). Key attributes of the MD process are that it is modular, its flux and product-water quality are insensitive to feed-water salinity up to about 200,000 ppm ((Syed Amir Basha, 2011; Adham et al., 2013; Xu et al., 2016)), products a product water with distillate-like quality $(<10 \mathrm{ppm})$, it is less prone to fouling than pressure-driven membranes (Alkhudhiri et al., 2012), and it requires a small footprint. Depending on operational conditions, product water recovery $(R)$ can reach (more than) $90 \%$, with recirculation of the brine stream providing increased $\mathrm{R}$. The two key focus areas in further evolution of the process are MD membrane improvements (higher flux, higher hydrophobicity (contact angle), and lower wettability) and 
appropriate process configuration (Camacho et al., 2013); while much bench-scale work has been done with direct contact MD (DCMD) (Francis et al., 2014a, Francis et al., 2014b), air gap MD (AGMD) (Alsaadi et al., 2013, Alsaadi et al., 2015) and vacuum MD (VMD) (Alsaadi et al., 2014) are receiving more attention because of their more favorable energetics. Recent progress has been made in fabricating hollow fiber and multi-bore MD membranes (Francis et al., 2014c; Wang and Chung, 2013; Drioli, et al., 2013)). Module scale-up with efficient internal heat recovery and satisfactory flux remains one of the main challenges of the MD process (Guillén-Burrieza et al., 2012; Winter et al., 2011; Francis et al., 2014a). While some companies market their watertreatment hollow fiber microfiltration (MF) membranes as MD membranes, they do not always possess the desired properties. There are several (European) companies that have pilot-tested MD, demonstrating the potential and feasibility of the MD process (Cipollina et al., 2012), and are now marketing MD units with different configurations and capacities; however, most of these have largely been confined to AGMD systems with flat-sheet membranes.

MD requires energy input in two forms: thermal (to drive the separation process) and electrical (to move feed, product, and brine flows). MD can meet the targeted energy threshold if powered by waste heat to satisfy the thermal power requirement $(>100$ $\mathrm{kWh} / \mathrm{m}^{3}$ ) (Camacho et al., 2013), with only about $1.0 \mathrm{kWh} / \mathrm{m}^{3}$ of electrical power needed (Singapore Public Utilities Board (PUB), personal communication). A key challenge is integration of waste heat recovery and utilization into the overall MD system. When coupled with solar energy, solar-MD can serve off-the-grid locations while providing a reduction in GHG emissions. Also of interest is MD processing of saline feed streams containing latent heat (e.g., thermal desalination brines or oil-and-gas produced water). Fouling in MD is significantly lower than that encountered in conventional pressuredriven membrane separation, and scale inhibitor and acid may be required to prevent scaling. There is emerging interest in MD as part of a zero liquid discharge (ZLD) scheme for inland desalination in which recovery is further increased to approach crystallization, and the process then becomes membrane distillation crystallization (MDC).

Pressure retarded osmosis (PRO), a variation of $\mathrm{FO}$, can produce salinity gradient (blue) energy from a feed and draw solution with an osmotic-pressure gradient, with pressure created by flow of freshwater into salt water. The resultant salinity gradient energy can be used to power a turbine, or can be integrated into a SWRO ERD. There has been significant improvement in PRO membranes in terms of flux, rated pressure (bar), and power density $\left(\mathrm{W} / \mathrm{m}^{2}\right)$ (Chung et al., 2015); Zhang and Chung reported hollow fiber PRO membranes with $24 \mathrm{~W} / \mathrm{m} 2$ at 20 bar. Straub et al. (2016) identified three potential PRO configurations: (i) systems located where rivers discharge into the sea, (ii) systems that can potentially utilize the high concentration gradients available from hypersaline solutions; and (iii) PRO integrated into SWRO plants to reduce electricity requirements. The most visible PRO demonstration project, operated in Norway by Statkraft, recently ceased PRO operations based on use of seawater and river water, with its failure attributed to low power density PRO membranes, PRO membrane fouling, and an inadequate osmotic-pressure gradient. There is now interest in coupling SWRO brine with a wastewater effluent, having a higher osmotic-pressure gradient (Achilli et al., 2014), with an added advantage being brine dilution for safe marine 
disposal; the PRO harvested energy can be used to offset SWRO energy requirements. Sarp et al. (2016) has projected that an integrated PRO process can provide about 20 $\%$ reduction in SWRO specific energy consumption for a typical SWRO brine; thus, one can estimate an potential PRO offset to SWRO of about $0.5 \mathrm{kWh} / \mathrm{m}^{3}$. In Japan, the recent MEGATON project achieved a power density of $>10 \mathrm{~W} / \mathrm{m}^{2}$ using a $7 \%$ SWRO brine in a demonstration-scale study using PRO membrane modules (Kurihara, 2015). In Singapore, a PRO system using SWRO brine and wastewater RO (WWRO) brine is being studied (Wan and Chung, 2015), where WWRO brine has no economic value. Both of these approaches would necessitate co-location of seawater desalination and wastewater treatment/reclamation facilities.

Reverse electrodialysis (RED) is another membrane-related salinity energy gradient process, building upon the electrodialysis (ED) process. Like ED, RED employs an array (stack) of cation (CEM) and anion (AEM) exchange membranes to transport ions (not water), with electrodes capturing electrical current associated with the flow of ions. Key issues for further process development include improved (thinner, lower resistance) CEM and AEM membranes, optimal stack configuration, and applications involving a higher osmotic-pressure gradient. Work by Vermaas et al. (2013) showed the dependence of RED energy efficiency on the ratio between the magnitudes of flow, flow directions (counter- versus co-) of higher salinity water (e.g., seawater) and lower salinity water (e.g., river water flow), and the number of electrode segments. As with PRO membranes, a targeted attribute of RED membranes is power density $\left(\mathrm{W} / \mathrm{m}^{2}\right)$. An existing demonstration project in the Netherlands (http://www.redstack.nl) involves the use of North Sea water and ljssel Lake (derived from the Rhine River) water, separated by a dike. An advantage of RED versus PRO is that electricity is generated directly from a salinity gradient (Logan and Elimelech, 2012).

All of the discussed membrane processes, conventional and emerging, have inherent fouling challenges and associated pretreatment requirements. However, these vary among process, e.g., $\mathrm{FO}$ is less prone to irreversible fouling than $\mathrm{RO}$ and requires less pretreatment (Valladares, et al., 2014) whereas scaling represents the main challenge for MD versus biofouling for RO. In this paper, we have chosen not to consider energy reductions in pre-treatment in order to focus on the energetics of the desalting process itself, the main energy sink, although it is recognized that fouling affects energy consumption. Moreover, while there is a need for antifouling membranes, including RO, this topic is considered to be beyond the scope of this paper.

\subsection{Emerging Process Niches and Hybrids}

It is debatable whether any of the aforementioned processes will, in the near or even a long term, replace SWRO as the conventional seawater desalination technology. However, there are other niche applications of interest, e.g., (i) use of FO in brine concentration in managing produced water from fracking and (ii) use of MD in brine concentration and a step toward zero liquid discharge (ZLD) in inland desalting applications. Among the many possible hybrid systems, potential hybrids of interest include: (i) the aforementioned FO-LPRO hybrids for indirect seawater desalination; (ii) SWRO-PRO/-RED in which PRO-/RED-generated energy offsets SWRO energy requirements; (iii) FO-MD in which (waste heat-driven) MD plays a role in recycling draw solution components; (iv) MD-PRO/-RED in which a higher salinity MD brine is used to 
drive PRO/RED; and (v) MSF- (or MED-) MD in which the latent heat of the thermal brine is used to recover additional water.

\begin{tabular}{|c|c|c|c|}
\hline Process & Driving Force & Potential Niches & Potential hybrids \\
\hline SWRO & (Applied) Pressure & Seawater Desalination. & \\
\hline CC-RO & (Applied) Pressure & Seawater Desalination. & \\
\hline FO & Osmotic Pressure & $\begin{array}{l}\text { Desalination, Produced Water } \\
\text { Treatment, Brine Concentration }\end{array}$ & FO-LPRO, FO-MD \\
\hline MD & Thermal Gradient & $\begin{array}{l}\text { Desalination, Produced Water } \\
\text { Treatment, Brine Concentration }\end{array}$ & FO-MD, MD-PRO, MD-RED \\
\hline PRO & Salinity Gradient & SWRO and MD Brines & SWRO-PRO, MD-PRO \\
\hline RED & Salinity Gradient & SWRO and MD Brines & SWRO-RED, MD-RED \\
\hline
\end{tabular}

8.0 Path Forward for Reducing Specific Energy Consumption and GHG Emissions

Fane et al. (2015) state that improvements are necessary in membranes, modules, and processes (i.e., membrane engineering). The present state-of-the-art is the SWRO process with an ERD system. Given the relatively lower energy requirement of SWRO pre- and post-treatment $\left(<0.5 \mathrm{kWh} / \mathrm{m}^{3}\right)$, our major focus is on the SWRO membrane process itself $\left(>2.5 \mathrm{kWh} / \mathrm{m}^{3}\right)$ in terms of UHP RO membranes or emerging processes.

In the near-term, CC-RO is now emerging into the commercial arena as well as FO and $M D$ in niche applications; however, improved-performance hollow-fiber FO and MD membranes will allow other, potentially more efficient FO and MD process configurations (versus commercially-available flat-sheet membranes). Recently, Evoqua Water, in a collaboration with the Public Utilities Board (PUB) of Singapore (http://www.desalination.biz/news/news_story.asp?id=6008), has developed an electrochemical system to desalt seawater, using electrodialysis (ED)/continuous electrodeioninzation (CEDI), with an estimated energy consumption of $<2.0 \mathrm{kWh} / \mathrm{m}^{3}$ based on pilot-testing; a demonstration plant is being constructed in partnership with PUB of Singapore to further scale-up and test the technology.

In the medium term (within 3 - 5 years), technology opportunities include integrated SWRO-PRO, the FO-LPRO hybrid, and waste heat-driven MD, with the latter needing further process integration of heat exchangers. While (fossil fuel) reductions will lead to a concomitant reduction in GHG emissions, further reductions can be realized by solardriven SWRO and, for off-the-grid applications, solar MD. Aquaporin-based UHP RO membranes are evolving from tap water to seawater applications.

On the further horizon (> 5 years), opportunities include other UHP (synthetic water channel or graphene) RO membranes, synthetic ion channel membranes, and novel electrochemical processes, separating salts from water versus water from salts (i.e., RO). However, the inherent osmotic penalty will restrict energy improvement by UHP membranes to $<0.5 \mathrm{kWh} / \mathrm{m}^{3}$. Two interesting opportunities are: (i) membranes incorporating synthetic ion channels and (ii) further evolution of CDI in transitioning from a brackish to a seawater technology in concert with materials-improvements in highercapacity electrodes and further process intensification to membrane-CDI (M-CDI). Synthetic ion channel membranes, depending on the specific channel, may function as either ion exchange membranes for cations or anions, or as a molecular gate for all ions. $\mathrm{M}-\mathrm{CDI}$ involves the integration and placement of cation and anion exchange 
membranes adjacent to the respective CDI electrodes to facilitate transport of co- and counter-ions, enhancing overall salt adsorption (Zhao, et al., 2012).

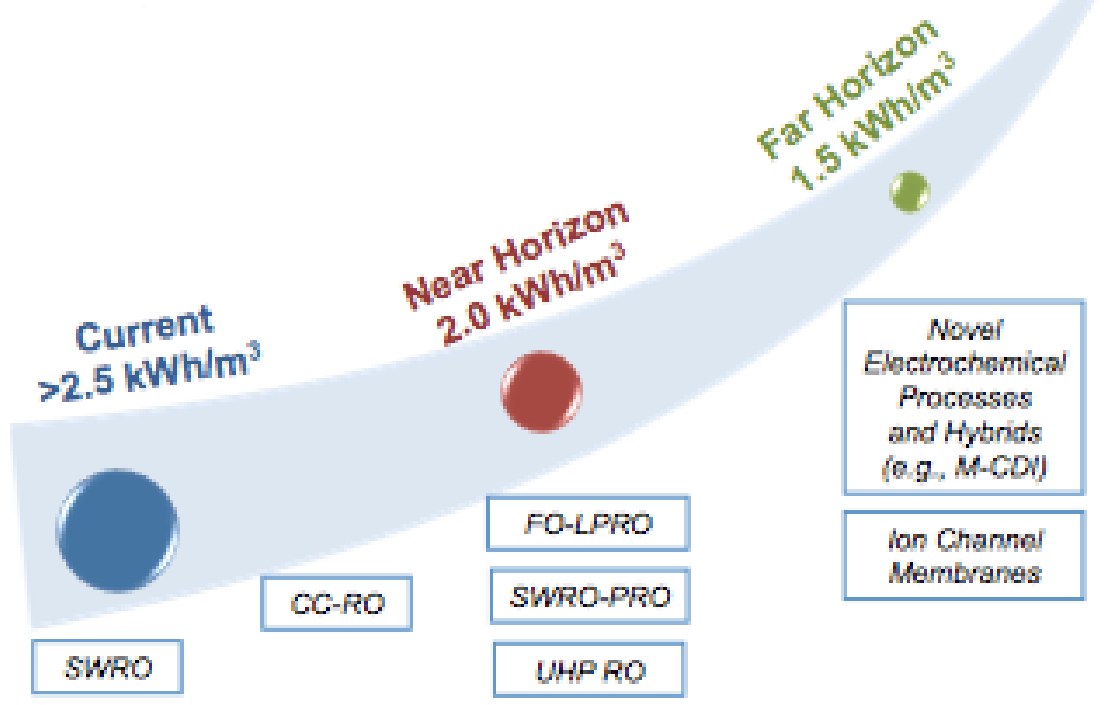

integrated MD-Waste Heat Recovery and Utization

Future research needs largely correspond to the medium-term (applied research) and far-horizon (basic research) opportunities summarized above. Future seawater desalination technology adoption should be based on a rigorous life cycle assessment (LCA) that goes beyond unit costs $\left(\$ / \mathrm{m}^{3}\right)$ and also takes into account environmental impact minimization. Given the recent interest in subsurface intakes, a careful energetic and environmental analysis is needed in comparison to open intakes, however, it is important to acknowledge that subsurface intakes may in themselves play the role of the SWRO pre-treatment process whereas open intakes require a separate pretreatment process with its own energy requirements. In addition, more stringent SWRO brine disposal requirements may lead to further energy investment in multi-port diffuser systems in order to achieve a restricted mixing zone. Technologies developed for seawater desalination will have broader impacts in their applicability to other saline streams including produced water.

\section{References}

Adham, S., Hussain, A., Matar, J.M., Dores, R., Janson, A., Application of Membrane Distillation for desalting brines from thermal desalination plants, Desalination 314, 101 108 (2013).

Alkhudhiri, A., Darwish, N., Hilal, N., Membrane distillation: A comprehensive review, Desalination 287, 2-18 (2012)

Achilli, A., Prante, J. L., Hancock, N. T., Maxwell, E. B., Childress, Amy, Experimental Results from RO-PRO: A Next Generation System for Low-Energy Desalination, Environ. Sci. Technol., 48 (11), 6437-6443 (2014). 
AlSaadi, A.S., Ghaffour, N., Li, J-D., Gray, S., Francis, L., Maab, H., Amy G.L., Modelining of Airgap Membrane Distillation. Journal of Membrane Science, 445, 53-65 (2013).

AlSaadi, A.S., Francis, L., Amy, G.L., Ghaffour, N., Experimental and theoretical analyses of temperature polarization effect in vacuum membrane distillation Journal of Membrane Science, 478, 138-148 (2014).

AlSaadi, A.S., Francis, L., Amy, G.L., Ghaffour, N., Evaluation of air gap membrane distillation process running under sub-atmospheric conditions: Experimental and simulation studies. Journal of Membrane Science, 489, 73-80 (2015).

Camacho, L. M., Dumée, L., Zhang, J., Li, J., Duke, M., Gomez, J., Gray, S., Advances in Membrane Distillation for Water Desalination and Purification Applications, Water, 5, 94-196; doi:10.3390/w5010094 (2013).

Chung, T-S, Luo, L., Wan, C. F., Cui, Y., and Amy, G., What is next for forward osmosis (FO) and pressure retarded osmosis (PRO), Separation and Purification Technology 156, 856-860 (2015).

Cipollina, A., DiSparti, M.G., Tamburini, A., Micale, G., Development of a membrane distillation module for solar energy seawater desalination, Chenical Engineering Research and Design, 90, 2101-2121 (2012).

Drioli, E., Simone, S., Macedonio, F., Al-Jlil, S.A., Al Shabona, F.S., Al-Romaih, H.S., Al-Harbi, O., Figoli, A., Criscuoli, A., Novel PVDF hollow fiber membranes for vacuum and direct contact membrane distillation applications, Separation and Purification Technology, Volume 115, 27-38 (2013).

Efrati, A., Closed circuit desalination series no-4: high recovery low energy desalination of brackish water by a new single stage method without any loss of brine energy, Desalination and Water Treatment, 31, 95-101 (2011).

Elimelech, M., and Philip, W., The Future of Seawater Desalination: Energy, Technology, and the Environment, Science 333, 712 (2011).

Fane, A. G., Wang, R. Hu, M. X., Synthetic Membranes for Water Purification: Status and Future, Angewandte Reviews, Angew. Chem. Int. Ed. 2015, 54, 3368 - 3386 (2015).

Francis, L., AlSaadi, A.S., Ghaffour, N., Nunes, S.P., Amy, G.L., Performance evaluation of the DCMD process under bench scale and large scale module operating conditions. Journal of Membrane Science 445, 103-112 (2014a).

Francis, L., AlSaadi, A.S., Ghaffour, N., Amy, G.L., PVDF hollow fiber and nanofibers membranes for fresh water reclamation using membrane distillation; Journal of Materials Science, 49, 2045-2053 (2014b).

Francis, L., Ghaffour, N., AISaadi, A.S., Amy, G.L., Fabrication and Characterization of Functionally Graded PVDF-Silver Nanocomposite Hollow Fibers for Sustainable Water Recovery. Science of Advanced Materials, 6 (12) 2659-2665 (2014c).

Ghaffour, N., Lattemann, S., Missimer, T., Sinha, S., Amy, G., Renewable energy-driven innovative energy-efficient desalination technologies, Applied Energy, 136, 1155-1165 (2014). 
Ghaffour, N., Missimer, T.M., Amy, G.L., Technical review and evaluation of the economics of water desalination: Current and future challenges for better water supply sustainability, Desalination 309, 197-207 (2013).

Ghaffour, N., Bundschuh, J., Mahmoudi, H., Goosen, M.F.A., Renewable energy-driven desalination technologies: A comprehensive review on challenges and potential applications of integrated systems, Desalination 356, 94-114 (2015).

Global Water Intelligence/Water Desalination Report (GWIMDR), 2015.

Guillén-Burrieza, E., Zaragoza, G., Miralles-Cuevas, S., Blanco, J., Experimental evaluation of two pilot-scale membrane distillation modules used for solar desalination, Journal of Membrane Science 409-410, 264-275 (2012).

Hancock, N. T., Black, N. D., Cath, T. Y., A comparative life cycle assessment of hybrid osmotic dilution desalination and established seawater desalination and wastewater reclamation processes, Water Research, 46, 1145 - 1154 (2012).

Kurihara, M., Role of Pressure Retarded Osmosis (PRO) in the MEGATON Project, http://www.desaltech2015.com/assets/presenters/Kurihara_Masaru.pdf (2015).

Lattemann, S., Kennedy, M.D., Amy, G., Seawater desalination - A green technology?, Journal of Water Supply: Research and Technology - AQUA 59 (2-3), 134-151 (2010).

Lattemann, S., Development of an Environmental Impact Assessment and Decision Support System for Seawater Desalination Plants, PhD Dissertation, Technical University of Delft (2010).

Logan, B. E., and Elimelech, M., Membrane-based processes for sustainable power generation using water, Nature, 488, 313 (2012).

McGinnis, R. L., Hancock, N. T., Nowosielski-Slepowron, M.S., McGurgan, G. D., Pilot demonstration of the $\mathrm{NH}_{3} / \mathrm{CO}_{2}$ forward osmosis desalination process on high salinity brines, Desalination 312, 67-74 (2013).

McGovern, R., and Lienhard, J., On the Potential of Forward Osmosis to Energetically Outperform Reverse Osmosis Desalination, Journal of Membrane Science 469, 245-50. (2014).

Missimer, T.M., Ghaffour, N., Dehwah, A.H.A., Maliva, R.G., Amy, G., Subsurface intakes for seawater reverse osmosis facilities: Capacity limitation, water quality improvement, and economics, Desalination, 322, 37-51 (2013).

Pendergast, M. M., and Hoek, E. M. V., A review of water treatment membrane nanotechnologies, Energy Environ. Sci., 4, 1946 (2011).

Rahmawati, K., Ghaffour, N., Aubry, C., Amy, G.L., Boron removal efficiency from Red Sea water using different SWRO/BWRO membranes, Journal of Membrane Science 423-424, 522-529 (2012).

Sarp, S., Li, Z., Saththasivam, J., Pressure Retarded Osmosis (PRO): Past experiences, current developments, and future prospects, Desalination, Article in Press (2016).

Shaefer, D.L., Werber, J.R., Jaramillo, H., Lin, S., Elimelech, M., Forward osmosis: Where are we now? , Desalination, 356, 271-284 (2015).

Shen, Y., Si, W., Erbakan, M., Decker, K., De Zorzi, R., Saboe, P.O., Kang, Y.J., Majd, 
S. Butler, J., Walz, T., Aksimentiev, A., Hou, J.I., Kumar, M., Highly permeable artificial water channels that can self-assemble into two-dimensional arrays, PNAS, 112, 32, 9810-9815 (2015).

Straub, A. P., Deshmukh, A., and Elimelech, M., Pressure-retarded osmosis for power generation from salinity gradients: is it viable?, Energy Environ. Sci., 2016,9, 31-48 (2016).

Subramani, A., Jacangelo, J. G., Emerging desalination technologies for water treatment: A critical review, Water Research 75, 164 -187 (2015).

Sukitpaneenit, P., and Chung, T.S., High performance thin-film composite forward osmosis hollow fiber membranes with macrovoid-free and highly porous structure for sustainable water production, Environ Sci Technol., 46(13):7358-65 (2012).

Suss, M. E., Porada, S., Sun, X., Biesheuvel, P. M., Yoon, J., Presser, V., Water desalination via capacitive deionization: what is it and what can we expect from it?, Energy Environ. Sci., 8, 2296-2319 (2015).

Syed Amir Basha, K., Membrane distillation test for concentration of $\mathrm{RO}$ brine at WESSCO - Jeddah, IDA World Congress - Perth Convention and Exhibition Centre (PCEC), Perth, Western Australia September 4-9, 2011, Ref: IDAWC/PER11-351.

Valladares Linares, R., Li, Z., Yangali-Quintanilla, V., Ghaffour, N., Amy, G., Leiknes, T., Vrouwenvelder, $\mathrm{H}$., Life cycle cost of a hybrid forward osmosis - low pressure reverse osmosis (FO-LPRO) system for seawater desalination and wastewater recovery, Water Research, 88, 225 - 234 (2016).

Valladares Linares, R., Li, Z., Sarp, S., Sz.S. Bucs, S., Amy, G., Vrouwenvelder, J. S., Forward osmosis niches in seawater desalination and wastewater reuse, Water Research, 66, 122-139 (2014).

Valladares Linares, R., Li, Z., Abu-Ghdaib, M., Wei, C.H., Amy, G.L., Vrouwenvelder, J.S., Water harvesting from municipal wastewater via osmotic gradient: An evaluation of process performance, Journal of Membrane Science 447, 50-56 (2013).

Vermaas, D. A., Veerman, J., Yip, N. Y., Elimelech, M., Saakes, M., Nijmeijer, K., High Efficiency in Energy Generation from Salinity Gradients with Reverse Electrodialysis, ACS Sustainable Chem. Eng. 1, 1295-1302 (2013).

Villacorte, L.O., Tabatabai, A.A., Anderson, D.M., Amy, G.L., Schippers, J.C., and Kennedy, M.D., Seawater reverse osmosis desalination and (harmful) algal blooms, Desalination, Volume 360, 61-80 (2015).

Voutchkov, N., Considerations for selection of seawater filtration pretreatment system, Desalination, Volume 261, 354-364 (2010).

Wan, C. F., and Chung, T. S., Osmotic power generation by pressure retarded osmosis using seawater brine as the draw solution and wastewater retentate as the feed Journal of Membrane Science, 479, 148-158 (2015).

Wang, P., and Chung, Tai-Shung, A New-Generation Asymmetric Multi-Bore Hollow Fiber Membrane for Sustainable Water Production via Vacuum Membrane Distillation, Environ. Sci. Technol., 47 (12), 6272-6278 (2013).

Xu, J., Singh, Y.B., Amy, G.L., Ghaffour, N., Effect of operating parameters and membrane characteristics on air gap membrane distillation performance for the 
treatment of highly saline water, Journal of Membrane Science 512, 73-82 (2016).

Winter, D., Koschikowski, J., Wieghaus, M., Desalination using membrane distillation: Experimental studies on full scale spiral wound modules, Journal of Membrane Science 375, 104-112 (2011).

Zhang , S., and Chung, T.S., Minimizing the instant and accumulative effects of salt permeability to sustain ultrahigh osmotic power density, Environmental Science \& Technology, 47, 10085-10092 (2013).

Zhao, R. Biesheuvel, P.M., van der Wal, A., Energy consumption and constant current operation in membrane capacitive deionization, Energy \& Environmental Science. 5 (11): 9520-9527 (2012). 